\title{
Cambio de estatutos: Acercando la Sociedad a los cirujanos de Chile
}

\section{Change of statutes: Approaching the Society to the surgeons}

Nuestra Institución nace de la unión de la Sociedad de Cirugía de Chile fundada en 1922 y la Sociedad de Cirujanos de Hospital fundada en 1931.

Adquiere su personalidad jurídica en el año 1949 y pasa a llamarse Sociedad de Cirujanos de Chile.

Sus estatutos se han reformado en dos ocasiones, en el año 1956 y en 1986.

Estos últimos son los que actualmente nos rigen.

Debido a la inquietud de muchos cirujanos a lo largo de Chile y con el fin de hacer la sociedad más participativa y flexible, en el LXXVI Congreso en Viña del Mar en Diciembre de 2003, en una asamblea extraordinaria, con la presencia de 53 socios titulares se aprueba la reforma de los estatutos vigentes, reforma que había sido discutida en el seno del Directorio desde el año anterior.

Han pasado 6 años desde aquella reunión y creo importante que los Cirujanos de Chile conozcan las reformas que se van a poner en práctica y que harán de nuestra Sociedad un referente más sólido y representativo de sus pares. Queremos ser líderes en el ambiente médico no sólo en lo que se refiere a las actividades cientificas sino que también en temas importantes como la certificación y re-certificación de la especialidad, la evaluación de calidad-costo-efectividad de la atención quirúrgica pública y privada, en temas relacionados con la judicialización de la Medicina y otros. De este modo, podremos establecer diálogos constructivos y productivos frente a las autoridades de Gobierno e Instituciones prestadoras de salud.

Dentro de estas reformas quiero destacar 7 artículos que vale la pena recordar y revisar:

Ser miembro titular de la Sociedad es un anhelo de muchos cirujanos, pero el requisito de presentar un trabajo inédito era un escollo muchas veces difícil de vencer ya que requería años de ejercicio profesional para acumular y tabular la experiencia personal.

Con el cambio del artículo cuarto ahora podrán ingresar como miembros titulares todos aquellos médicos que tengan la certificación de especialista otorgada por una Institución, con un programa de especialización acreditado, o por CONACEM, ser presentado por tres miembros titulares, aprobado por el Directorio, cumplir con disposiciones y cuotas legales, estatutarias y reglamentarias aplicables a la Sociedad, debiendo además cumplir con uno de los siguientes requisitos:

a) Haber presentado al menos un trabajo cientifico inédito.

b) Pertenecer como miembro afiliado al menos tres años, con asistencia a dos congresos anuales de la Sociedad.

c) Haber presentado 2 trabajos libres en seccionales del congreso y/o haber publicado en la revista de la sociedad como autor o co-autor.

d) Haber hecho una contribución a la especialidad.

De este modo, muchos de los miembros afiliados podrán tener la categoría de titulares y los que aún no pertenecen a la sociedad podrán hacerlo sin mayores dificultades.

No dejará de existir la categoría de miembros afiliados, sobretodo para aquellos cirujanos jóvenes, los que en tres años podrán cambiar su membresía a titular cumpliendo algunos de los requisitos antes mencionados. 
El cambio en este artículo es fundamental para lograr ser realmente representativos de todos los cirujanos a lo largo de Chile. Para ser escuchados es importante que todos aquellos médicos especialistas en Cirugía tengan un nexo con la sociedad y que participen activamente, no sólo en las actividades científicas, sino también en su directorio, eligiendo a quienes la mayoría crea que va a representar mejor sus inquietudes.

La situación geográfica de nuestro país no debería ser un impedimento, dado los notables avances en las comunicaciones por medio de internet, telefonía celular y otros.

Se eliminó parte del artículo 10 en que sólo miembros titulares tenían derecho a participar en actividades cientificas de la Sociedad dejando abierta esta posibilidad a todo especialista con méritos para presentar su experiencia en las distintas instancias cientificas que tiene la sociedad a lo largo del año.

Los miembros titulares continúan con la exclusividad de participar en lo referente a cambio de estatutos, disolución de sociedad, elección de directorio, ocupar cargos y participar en asambleas ordinarias y extraordinarias con derecho a voz y voto.

En cuanto a la composición del directorio y su duración, se realizaron varios cambios que tienen como finalidad tener mayor representación de los socios y una mejor continuidad a las distintas ideas que se propongan. El artículo 16 cambia y aumenta los directores de 8 a 9. Al modificar el artículo 17 el presidente y vicepresidente durarán 2 años en su cargo. Anualmente se elegirán 9 directores, los que pueden ser reelegidos. El tener un Directorio más estable ayuda a que los proyectos tengan tiempo para concretarse bajo una misma dirección.

Los estatutos que nos rigen hasta ahora exigian que la asamblea general ordinaria anual tuviera que ser la primera quincena de diciembre. Durante muchos años en que he participado en ella, sólo veo cirujanos de Santiago, representantes de los capítulos y miembros del directorio; con ese quórum se realiza la elección para la renovación de los miembros del Directorio que corresponda. El cambio del artículo 35 permite que esta asamblea se pueda realizar entre los meses de septiembre y diciembre, de preferencia durante el congreso anual, lo que permitirá una mayor participación de socios que se presenten como candidatos al comité ejecutivo o como directores y ejerzan su derecho a voto.

También se modificaron los requisitos de los postulantes. Para director, el nuevo estatuto exige tener 3 años de socio titular en vez de 5 y para presentarse al comité ejecutivo 5 en vez de 10.

Esto es muy importante ya que permitirá a cirujanos jóvenes, con entusiasmo e ideas renovadoras, participar en la dirección de nuestra corporación.

Finalmente se cambia el artículo 49, estableciendo que en caso de disolución de la sociedad los haberes de ésta no pasarán a la Universidad de Chile como estaba establecido, sino al Colegio Médico de Chile. Esperando que este hecho nunca ocurra, lo justo es que los bienes no los herede una sola Universidad sino una entidad común a la mayoría de nuestros socios.

Espero que lo que fue aprobado por una asamblea en el año 2003, este año logre plasmarse en una realidad concreta y renovemos nuestro Directorio en diciembre de este año con un número importante de socios de todo Chile, participando y entregando su voto durante el LXXIII Congreso Chileno e Internacional de Cirugía en Pucón.

Dra. Jamile Camacho N. Presidenta Sociedad de Cirujanos de Chile 